\title{
La incorporación al mercado laboral de la mujer inactiva: su distribución en España a finales del segundo milenio
}

\author{
Ma del PILAR Borderías URibeondo
}

\begin{abstract}
RESUMEN ABSTRACT
Desde el marco teórico de la

From the theoretical framework of Geografía, el artículo establece una inicial diferenciación espacial de la actividad femenina y de sus caracteristicas laborales, tras una reflexión sobre el cambio de la tradicional situación de cinactividad económica" de la mujer a lo largo de la década de los 90 y del análisis de los condicionantes que repercuten en su incorporación al mercado laboral: la edad, el estado civil, su nivel de instrucción y la discriminación Geography, the article establishes an initial spatial differentiation of the feminine activity and its labour characteristics, after a reflection over the change of woman's traditional role of "economic inactivity" along the 90 's, and of the analysis of the factors that have an effect on her joining the labour market: age, social state, level of studies and indirect discrimination.

indirecta.
\end{abstract}

\section{INTRODUCCIÓN}

La incorporación de las mujeres al mercado de trabajo ha constituido uno de los fenómenos más característicos de nuestro siglo en los países desarrollados, no obstante, las tasas de inactividad femenina en nuestro país siguen siendo muy elevadas. En España se ha pasado de unas tasas de inactividad femenina del $88,2 \%$ en 1950 al $64,93 \%$ en 1996 , quedando 
todavía por encima del porcentaje que se registra en los paises de la Unión Europea.

El incremento del número de mujeres que trabaja fuera del hogar en empleos remunerados no ha sido un fenómeno lineal ni homogéneo, sino que ha ido acorde con el desarrollo y la crisis industrial, y con diversos condicionantes sociales e ideológicos. Así, los períodos de mayor incorporación de las mujeres al trabajo han respondido a los ciclos económicos que se ha atravesado en cada momento, siendo una realidad la existencia de mano de obra potencial femenina que actúa de reserva, incorporándose o retirándose del mercado de trabajo en función de las oscilaciones del ciclo del empleo. Para un significativo grupo de mujeres aún puede seguir vigente aquella frase que apuntaban años atrás los grupos más radicales cuando señalaban que la mujer constituye un ejército de reserva laboral siendo "un asalariado potencialmente en paro cuando trabaja y un posible asalariado cuando permanece en el hogar".

De hecho, la integración plena de las mujeres en la economía sigue siendo una preocupación importante dada la significativa discriminación de la mujer en el ámbito laboral; buena prueba de ello es el esfuerzo efectuado, tanto por el Estado como por la Unión Europea, para desarrollar planes de igualdad que posibiliten y favorezcan su inserción laboral. En este sentido, se han realizado numerosos estudios sobre la participación de las mujeres en el mercado de trabajo, animados fundamentalmente por organismos internacionales como la ONU, la OIT, la OCDE y la UE, y por el impulso del movimiento de mujeres. En España el Instituto de la Mujer ha tenido un peso importante, al igual que los trabajos realizados en el marco de la Comunidad Económica Europea, alentados a través de la Comisión para la mujer y la Dirección General de Trabajo.

En las páginas que siguen, y a partir del análisis de parámetros fundamentales de carácter estructural, como son la actividad, ocupación, y paro, analizaremos la distribución en nuestro país de la situación de las mujeres en el mercado de trabajo.

\section{EVOLUCIÓN DE LA SITUACIÓN LABORAL DE LA MUJER ESPAÑOLA EN LA DÉCADA DE LOS 90}

La mujer española entra en la década de los noventa con un decidido propósito de incorporación al mercado laboral, puesto de manifiesto por el progresivo incremento de la tasa de actividad femenina, muy significativa 
si tenemos en cuenta que en tan sólo dieciseis años, desde 1980, esta tasa se ha incrementado en un $117.5 \%$, y en un $215.25 \%$ en relación con los años cincuenta. En cambio, las tasas de empleo y paro han tenido una evolución muy distinta, puesto que el empleo femenino, con sus altibajos, apenas ha crecido en esta década, y el paro femenino, muy superior al masculino, está por encima de la tasa de los años ochenta (25,5 en 1985, 29,1 en 1996), con una subida constante hasta 1994, en que comenzará su descenso con un año de retraso en relación con los hombres, desfase significativo que muestra la situación desfavorable en la que se encuentra la integración laboral de la mujer.

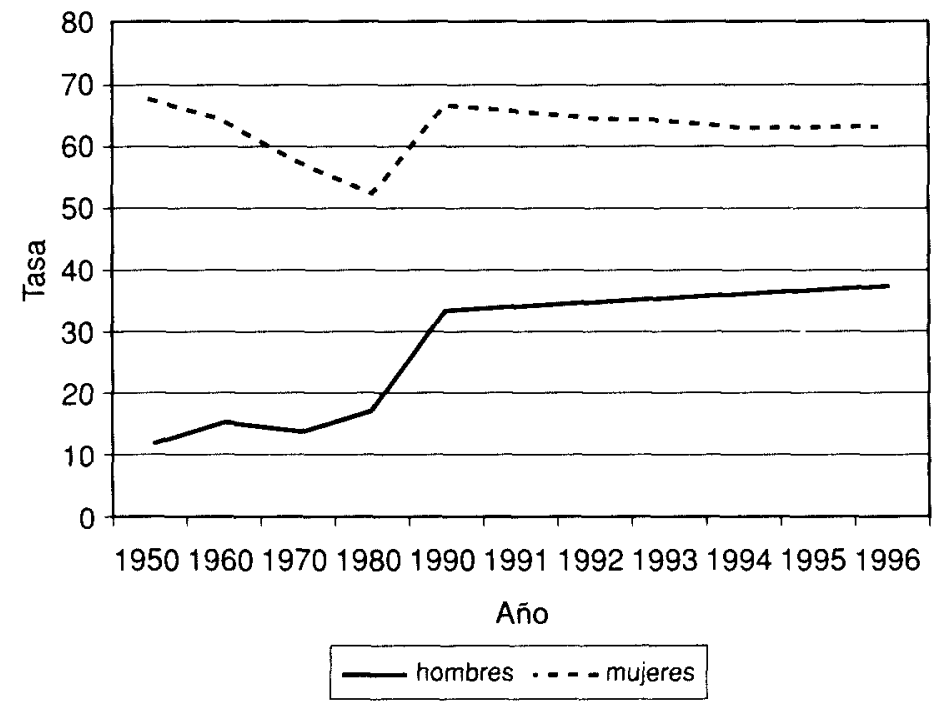

Gráfico 1. Evolución de la tasa de actividad por sexo.

A pesar de la tendencia de alza continuada de la tasa de actividad femenina, que contrasta con la masculina que ha descendido en los últimos diez años, la presencia de las mujeres en el mercado de trabajo sigue siendo muy inferior a la de los hombres, condicionada todavía por la distribución de papeles sociales según el género. En términos comparativos, también queda por debajo de los valores que se registran en la mayoria de los países de nuestro entorno económico, aunque resulta ser el país que mayor cambio ha registrado en su tasa de actividad desde 1985, año en que era el pais con menor actividad femenina (el 26,5, frente a Italia que le seguía con un 32,4 , y a una gran distancia de Dinamarca que tenía una 
tasa de 58,7). Actualmente su tasa del 37,2 queda a menor distancia de Dinamarca, que ha descendido al 45,2 , y está por encima de Italia $(36,9)$ y a la par que Grecia.

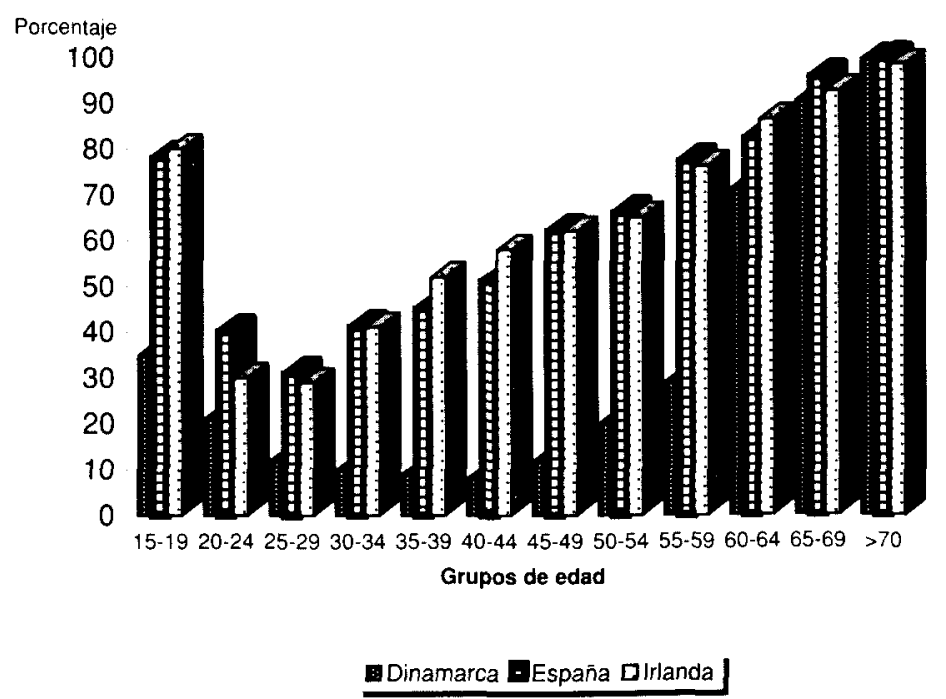

Gráfico 2. Inactividad femenina según la edad en la UE (contraste entre España y los países con mayor y menor tasa de inactividad).

En general, la inactividad sigue siendo importante en algunos países como el nuestro (gráfico $\mathrm{n}^{\circ} 2$ ), aunque con un manifiesto descenso en los grupos más jóvenes y con una evolución similar en todos los países, aunque en distinto grado, según los grupos de edad. La asignación social e ideológica del trabajo doméstico a las mujeres sigue creando dificultades para su incorporación laboral en muchos países, de hecho, la mujer se encuentra en el mercado de trabajo de una forma diferente al hombre, con unas expectativas y una jerarquía de valores diferentes. Por otro lado, si bien la mujer al tomar parte en el mercado de trabajo pasa a ser considerada como población activa, en realidad y para un importante grupo de ellas, la incorporación laboral no implica un descenso del número de mujeres que ejercen la producción doméstica a tiempo completo o «inactividad", sino más bien un aumento del número de mujeres que trabajan simultáneamente dentro y fuera del hogar.

Dentro de las situaciones de esta inactividad en España, es significativo el descenso de la dedicación a las labores del hogar, que ha pasado 
del $50 \%$ en 1984 al $34,07 \%$ en 1996 , de las cuales, además, el $75 \%$ son mujeres mayores de 39 años. Significativo es también que al mismo tiempo ha subido el número de mujeres estudiantes, con un porcentaje en 1996 del 10,29\%, superior al de los hombres que se sitúa en el $9 \%$. Alentadoras cifras para la incorporación laboral de la mujer basada, esencialmente, en el cambio de las nuevas generaciones.

Un aspecto que hay que tener en cuenta en el elevado porcentaje de inactividad que se observa, es la incidencia de la economía sumergida, en la que la mayoría de los empleos son ocupados por mujeres. Los índices de irregularidad laboral de las mujeres triplica a la de los hombres, y alrededor de la mitad de los ocupados en el mercado de trabajo irregular son mujeres. De hecho, en la pasada década se observó una creciente incorporación al mercado laboral sumergido de población oficialmente inactiva, sobre todo jóvenes y mujeres, estudiantes y amas de casa. Su actividad se centra sobre todo en formas de trabajo de tipo esporádico, a domicilio o a tiempo parcial, que les ofrece una amplia flexibilidad laboral, a los que se dirigen bien por necesidades familiares o por el deseo de una mayor autonomía frente a la institución familiar. Estos colectivos consideran estos trabajos como "ayudas" complementarias de los ingresos regulares, aunque, en su gran mayoría, acceden a estos empleos sumergidos o irregulares porque es lo único que se les ofrece.

Según un estudio del Ministerio de Economía y Hacienda, el índice de irregularidad podía alcanzar hasta el $60 \%$ en los servicios domésticos, actividad mayoritariamente ocupada por mujeres, un $42 \%$ en la confección, un $37,8 \%$ en la industria del calzado, un $34,5 \%$ en servicios personales, un $26,1 \%$ en la hostelería, etc. dando una media del $21,9 \%$ sobre el total de la ocupación.

\section{EDAD, ESTADO CIVIL Y NIVEL DE ESTUDIOS CONDICIONANTES DE LA INACTIVIDAD DE LA MUJER.}

Si bien en su conjunto hemos hablado de unas tasas de actividad femenina todavía bajas, hay que tener en cuenta la distribución de éstas, ya que la participación de la mujer en el mercado de trabajo no es homogénea debido a factores como la edad, el estado civil y los estudios realizados.

La edad constituye una de las variables que influyen en la presencia o ausencia de población activa femenina, dado que la tasa de actividad de las mujeres ha sido tradicionalmente muy sensible a partir de la edad de 
procreación. Las características de la actividad según sexo y edad en 1996 que nos muestra el cuadro $n^{\circ} 1$ evidencian la distinta composición y trayectoria de ambos sexos, pero también el cambio que está experimentando la situación de la mujer.

Cuadro 1. Contraste de las tasas de actividad, empleo y paro masculino y femenino según edad en 1991 y 1996.

\begin{tabular}{|c|c|c|c|c|c|c|c|c|c|}
\hline Edad & $\begin{array}{l}\text { T.A. } \\
\text { Mas. }\end{array}$ & $\begin{array}{l}\text { T.A. } \\
\text { Fem. }\end{array}$ & $\begin{array}{c}T . A . \\
\text { Fem. }\end{array}$ & $\begin{array}{l}\text { T.E. } \\
\text { Mas. }\end{array}$ & $\begin{array}{l}T . E . \\
\text { Fem. }\end{array}$ & $\begin{array}{l}\text { T.E. } \\
\text { Fem. }\end{array}$ & $\begin{array}{c}\text { T.P. } \\
\text { Mas. }\end{array}$ & $\begin{array}{l}\text { T.P. } \\
\text { Fem. }\end{array}$ & $\begin{array}{l}\text { T.P. } \\
\text { Fem. }\end{array}$ \\
\hline & 1996 & 1996 & 1991 & 1996 & 1996 & 1991 & 1996 & 1996 & 1991 \\
\hline 16 a 19 & 26.6 & 21.7 & 31.2 & 14.8 & 8.8 & 17.7 & 44.1 & 59.4 & 43.0 \\
\hline 20 a 24 & 63.1 & 56.5 & 61.4 & 41.8 & 30.7 & 37.9 & 33.7 & 45.6 & 38.2 \\
\hline 25 a 54 & 92.5 & 56.8 & 46.9 & 78.7 & 41.8 & 37.2 & 14.8 & 26.2 & 20.6 \\
\hline$>$ de 54 & 25.5 & 8.3 & 9.2 & 22.8 & 7.4 & 8.6 & 10.8 & 11.2 & 6.6 \\
\hline
\end{tabular}

Fuente: INE. CENSO/EPA.

La actividad masculina alcanza su máximo entre los 25 y los 54 años, tras los años de formación y servicio militar, mientras que la actividad femenina se estabiliza entre los 20 y 54 años, no experimentando el incremento masculino a partir de los 25 años, grupo en que cambia su estado civil, comienza su etapa de crianza, y empieza a desarrollar las funciones familiares que se le han asignado tradicionalmente. Pero si comparamos estos grupos con el año 1991, vemos que ha habido un importante cambio, al menos ya no desciende la actividad entre el grupo de 20-24 y 25-54 años sino que se mantiene, aunque por debajo de los valores de los hombres, que quedaban más próximos en el grupo de 16 a 19 años. Es pues notable el incremento experimentado por el grupo de 25-54 años, tal vez como resultado de la progresión de la integración a la actividad laboral de los grupos jóvenes de los últimos años. En general, a partir de los 35 años se produce cierta estabilización en la tasa de actividad femenina para registrar después de los 55 años una fuerte disminución, comparable a la de los hombres.

Precisamente, una de las principales diferencias entre el comportamiento laboral de hombres y mujeres estaba aquí, en la discontinuidad en la actividad que mostraban éstas en su período vital, explicada principalmente por la necesidad de atender a la familia. Por lo tanto, esta es una primera muestra de que la actitud de la mujer está cambiando en los años 90 , aunque la comparación de las tasas de empleo y paro respecto al otro 
sexo sigue mostrando sus graves problemas de inserción o de discriminación, pues, como ya mencionamos anteriormente, su tasa de empleo está muy por debajo y su tasa de paro muy por encima, al tiempo que ha bajado y ascendido respectivamente con relación a 1991.

Un hecho importante es el descenso de la actividad femenina experimentada por los grupos de 16 a 19 y de 20 a 24 años en 1996, puesto que ello supone un incremento de población estudiante en los niveles de estudios superiores, como lo corrobora el incremento de mujeres estudiantes dentro de la población inactiva.

Con respecto a la ocupación, los porcentajes según sexo y edad indican un mayor equilibrio hombre/mujer en los grupos de edad más bajos, experimentando una progresiva separación según aumenta la edad. Y no es precisamente la falta de formación lo que hace que la actividad de las mujeres esté tan marcada por el paro, ya que el valor del índice educativo de los parados es superior en las mujeres $(2,03$ frente a 1,84 en los hombres). Tampoco resulta favorable el hecho de que el sector servicios sea el que registre mayor porcentaje de paro (el $31 \%$ de los parados), puesto que en él trabaja el mayor porcentaje de mujeres, que representan además el $57,6 \%$ de parados del sector.

Estrechamente unido al factor edad, incide, como ya se ha señalado, el factor estado civil, por las connotaciones familiares que se asignan a la mujer. Resulta muy significativa la diferente tasa de actividad que se produce entre mujeres solteras y no solteras en relación con las casadas, de hecho las mujeres separadas-divorciadas, viudas jóvenes y solteras forman parte de la población activa de forma similar a la de los hombres mientras que las mujeres casadas son las que presentan tasas de actividad diferentes y muy inferiores. El gráfico no 3 nos permite ver cómo la población inactiva femenina casada tiene un progresivo incremento por grupos de edad mientras que en los hombres desciende a partir de la edad laboral.

A su vez, las diferencias de participación laboral de las mujeres según el estado civil se reduce o altera al relacionarlo con el nivel educativo, de modo que si bien se constata en general la incidencia en la menor disminución laboral que se produce en los grupos de mayor nivel educativo, resulta especialmente significativo en las mujeres casadas, que tienen mayor participación laboral al elevarse su nivel educativo. Esto refleja que la educación influye sobre la valoración ideológica de la tradicional división de funciones familiares, provocando actitudes favorables para su ruptura y para una mayor participación social de la mujer fuera del hogar. 


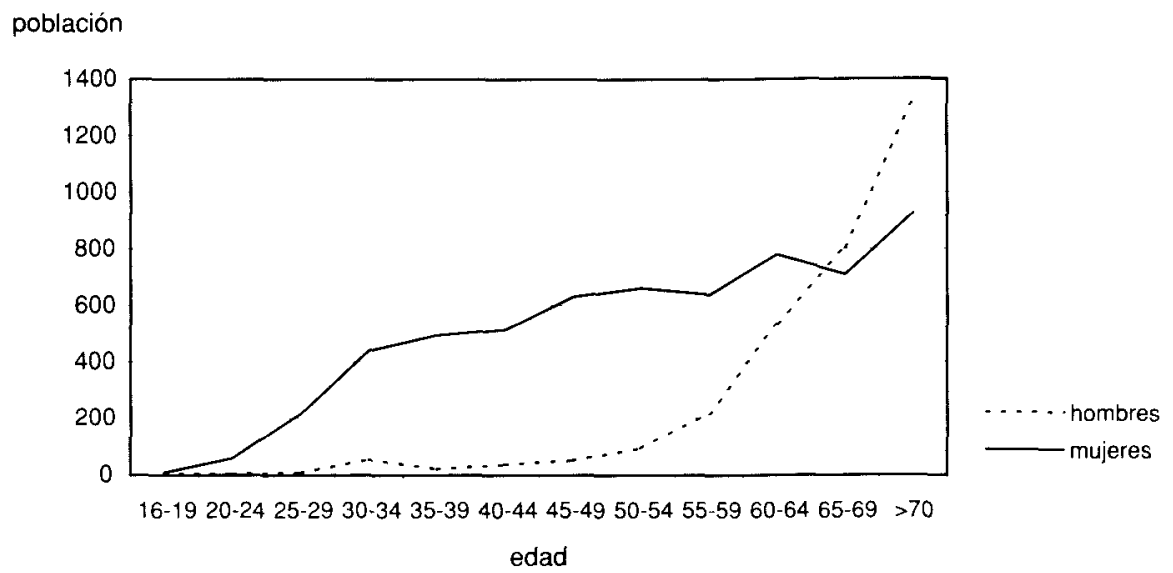

Gráfico 3. Evolución de la población inactiva casada según grupo de edad y sexo.

El acceso a la instrucción, unido a las campañas feministas y la toma de conciencia de los problemas profesionales son factores fundamentales en los cambios sociales en relación con la incorporación de la mujer al trabajo, de modo que la progresión hacia una mayor inserción sociolaboral de la mujer se debe en gran parte al mayor nivel de instrucción que va adquiriendo. Es notable el cambio experimentando en este sentido en los últimos años (gráficos $n^{\circ} 4$ y 5), reduciéndose la población femenina analfabeta y sin estudios a valores muy bajos en los grupos más jóvenes (por debajo de los 40 años en 1996), y alcanzando valores muy próximos a los hombres en los niveles superiores.

Este cambio en la capacitación y en la mentalidad, hace que, en general y para cada grupo de edad, el porcentaje de mujeres que trabaja sea superior cuanto mayor es el nivel de educación, excepto en los grupos de edad más bajos. De hecho se está incrementando la participación en los niveles de estudios medios y superiores, al tiempo que desciende o se estabiliza dicha participación en los niveles inferiores (sin estudios y primarios).

Según el índice educativo ponderado para los distintos niveles educativos $(E=3 P 1+2 P 2+1 P 3)$ siendo:

$$
\mathrm{Pt}
$$

$\mathrm{P1}$ : personas con estudios superiores.

P2: personas con estudios medios.

P3: personas con estudios primarios.

Pt: número total de personas de cada grupo de edad. 
La incorporación al mercado laboral de la mujer inactiva: su distribución en España...

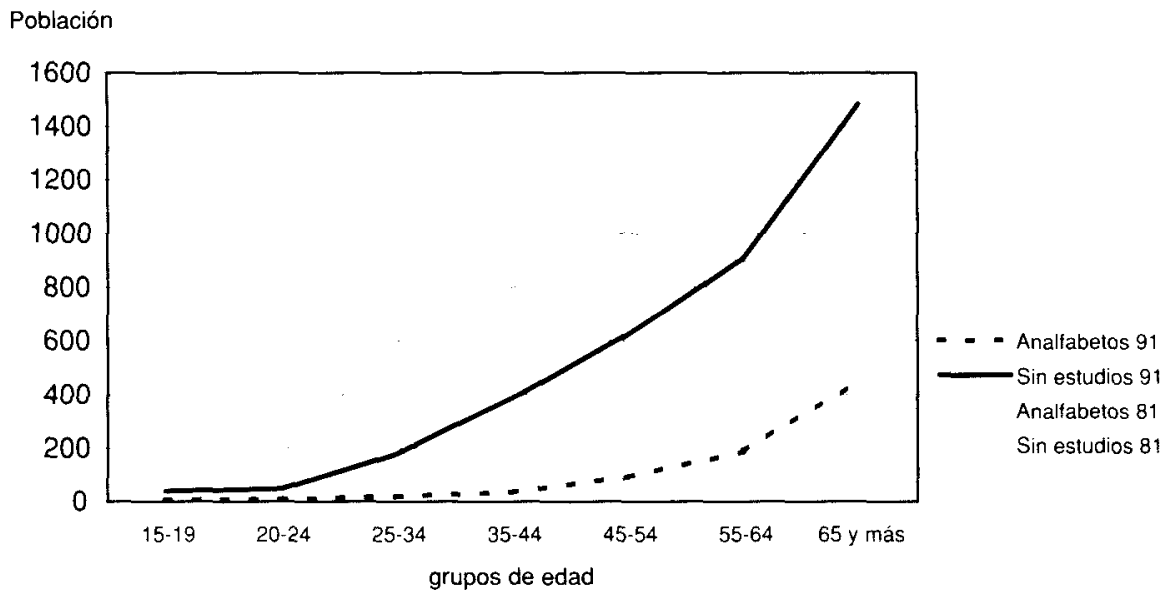

Gráfico 4. Mujeres con niveles de estudio inferiores según la edad.

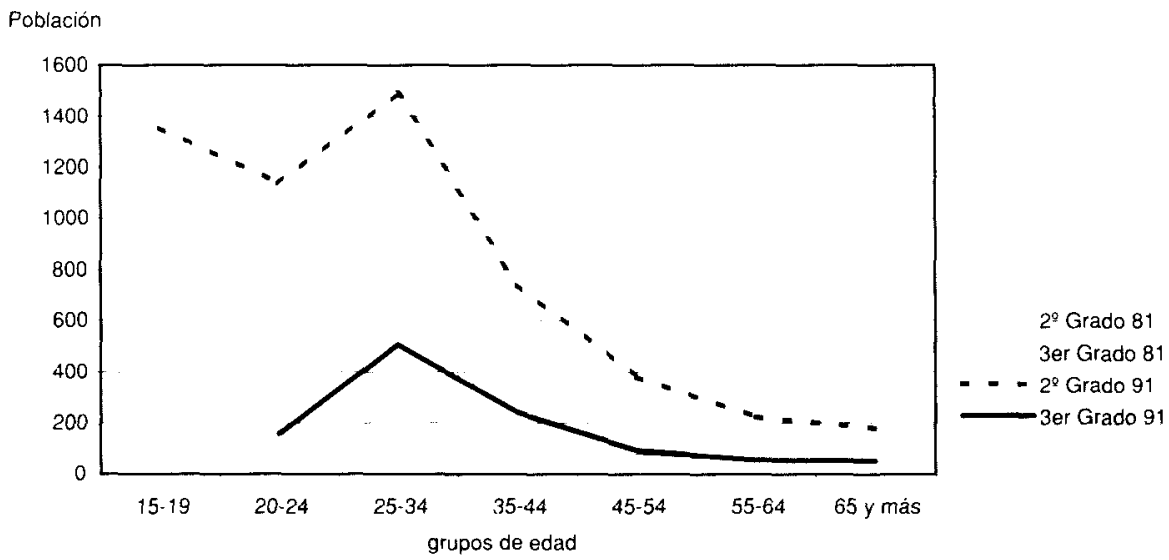

Gráfico 5. Mujeres con niveles de estudios superiores según la edad. 
Se obtienen los resultados del cuadro $n^{\circ} 2$. Según éste, el nivel educativo global es algo mayor en los hombres, pero si se analizan los resultados por grupos de edad encontramos que en los grupos más jóvenes el nivel educativo es superior en las mujeres, hasta el grupo de 30 años en 1991, lo que representa un avance con respecto a los datos del año 1983 en que el nivel educativo de la mujer resultaba inferior al de los hombres a partir del grupo de 25 años. A partir de esa edad el nivel educativo de la mujer es progresivamente más bajo. Lo cierto es que en el año 1991 la mujer ha alcanzado el nivel educativo medio de los hombres del año 1983 por lo que es de esperar que en no mucho tiempo llegue a equilibrarse. Podríamos hablar de un gran despegue educativo de la población, que se manifiesta especialmente en la mujer ya que partía de un nivel educativo inferior.

Cuadro 2. Indice educativo de la población total de 16 años y más por grupos de edad.

\begin{tabular}{lcccc}
\hline Grupo de edad & $\begin{array}{c}\text { Hombres } \\
1983\end{array}$ & $\begin{array}{c}\text { Hombres } \\
1991\end{array}$ & $\begin{array}{c}\text { Mujeres } \\
1983\end{array}$ & $\begin{array}{c}\text { Mujeres } \\
1991\end{array}$ \\
\hline De 15 a 19 & 1.73 & 1.74 & 1.76 & 1.80 \\
De 20 a 24 & 1.62 & 1.79 & 1.63 & 1.88 \\
De 25 a 29 & 1.49 & 1.81 & 1.43 & 1.88 \\
De 30 a 34 & 1.33 & 1.71 & 1.19 & 1.67 \\
De 35 a 39 & 1.20 & 1.54 & 1.06 & 1.43 \\
De 40 a 44 & 1.11 & 1.38 & 0.93 & 1.21 \\
De 45 a 49 & 0.99 & 1.23 & 0.81 & 1.03 \\
De 50 a 54 & 0.93 & 1.00 & 0.75 & 0.82 \\
De 55 a 59 & 0.89 & 0.87 & 0.72 & 0.70 \\
De 60 a 64 & 0.84 & 0.77 & 0.66 & 0.62 \\
De 65 a 69 & 0.79 & 0.71 & 0.57 & 0.56 \\
De 70 y más & 0.63 & 0.92 & 1.41 & 0.89 \\
Total & 1.17 & 1.29 & 0.99 & 1.17 \\
\hline
\end{tabular}

Fuente INE. Censo de población. EPA

Pero este elevado nivel educativo no resuelve las diferencias en el mercado laboral ya que, entre las personas que se encuentran en situación de demanda de empleo, la mayor diferencia porcentual entre sexos se da en los titulados medios y superiores, donde las mujeres demandantes de empleo representan el $70 \%$ y el $65 \%$ respectivamente. En cuanto a los demandantes de empleo con certificado de escolaridad, las mujeres representan el $44,2 \%$, y el $55,8 \%$ de los que tienen certificado de EGB. De 
hecho, las ocupaciones se jerarquizan teniendo en cuenta dos componentes, saber y responsabilidad, definida esta última como la "posesión de autoridad y capacidad de dirigir las actividades de otros", cualidades que todavía los empleadores asumen con dificultad en las mujeres.

\section{LA SEGREGACIÓN EN EL MERCADO DE TRABAJO}

Desde 1977, se ha realizado un importante esfuerzo para adaptar el ordenamiento jurídico español al principio de no discriminación por razón de sexo, recogido en varios artículos de la Constitución de 1978. Sin embargo, con frecuencia existe una gran diferencia entre las disposiciones legales y la práctica, por lo que se ha realizado un importante esfuerzo para establecer políticas específicas que integren a las mujeres en todos los ámbitos de la vida privada y pública.

La discriminación de la mujer en el mercado de trabajo sigue siendo una realidad que se pone de manifiesto en la diferencia entre ambos sexos en el grado de ocupación laboral, en el tipo de contrato, en el perfil laboral, o, lo que es más significativo, en el distinto sueldo que obtienen con los mismos estudios o con las mismas profesiones.

Evidentemente las mujeres tienen mayores dificultades para su contratación laboral. Si analizamos la información aportada por el INEM, resulta que de los cursos gestionados por este organismo en los niveles de formación ocupacional dentro del Plan FIP (Formación e Inserción Profesional) en 1996, a pesar de que el porcentaje de mujeres formadas es ligeramente superior al de los hombres (51\%-49\% respectivamente) su inserción laboral es menor (un $67,7 \%$ en el caso de los hombres y de un $57,2 \%$ en el de las mujeres). Solamente en el grupo de edad de menores de 20 años la tasa de inserción es ligeramente superior en las mujeres, en el resto, de 20 a 44 años la inserción femenina se distancia de la masculina según aumenta la edad. Es de destacar que en los grupos de mayores de 44 años no ha habido ninguna mujer en formación en el año 96, lo que nos está indicando el límite en el que se está revitalizando la incorporación de la mujer.

Pero además de las dificultades en la contratación, es frecuente que exista a su vez una significativa diferencia en cuanto al tipo de contrato. Las mujeres superan a los hombres en los siguientes tipos de contratos: tiempo parcial, interinidad, contratos en prácticas, y jóvenes menores de 25 años. Por el contrario, en los contratos indefinidos quedan por debajo $(33,96 \%)$ de estos. Si tenemos en cuenta que es la incorporación laboral 
de la mujer joven la que más incidencia está teniendo, tampoco le resultan favorables las estadísticas del tipo de contratos a menores de 25 años, en los cuales superan el $30 \%$ de los contratos eventuales, lanzamiento de nueva actividad y tiempo parcial; en cuanto a los de interinidad, obra y servicio, tiempo parcial indefinido y minusválidos se sitúan en torno al $28 \%$.

La concentración del empleo femenino es otro indicativo diferenciador. Tradicionalmente se explicaba que la falta de formación de la mujer era el impedimento para la diversificación, poniéndose como ejemplo de ello las pocas mujeres que se dirigían a la enseñanza técnica. Hoy día esta situación ha variado, en las nuevas generaciones, con relación a los niveles medios y superiores de estudios, equilibrándose los géneros en la asistencia a las aulas de carreras técnicas tradicionalmente ocupadas por los hombres, a pesar de lo cual sigue produciéndose el mismo fenómeno.

Si observamos los porcentajes de representación femenina en distintas ocupaciones, apreciamos inmediatamente la existencia de empleos y categorías femeninas y masculinos con prácticamente nula presencia de trabajadores del otro sexo. En el cuadro $n^{\circ} 6$ se relacionan las ocupaciones que han tenido más contrataciones en 1996, según datos del INEM, con la demanda femenina en cada ocupación y los índices de representación femenina en cada ocupación (la OCDE valora la segregación a través de los "índices de representación femenina" (IRF), definidos como relaciones entre los porcentajes de participación de la mujer en un empleo dado respecto a la participación de la mujer en el empleo total). A partir de estos datos podemos ver:

a) La discriminación que hace de sí misma la mujer, seleccionando determinadas profesiones a través de su demanda de trabajo. Así profesiones como camarera, mujer de limpieza, auxiliar de clínica, ATS, azafata, telefonista, o dependiente de comercio, tienen una demanda de mujeres superior al $85 \%$ del total de la demanda. Esto indica, por un lado, que sigue pesando todavía el tradicional concepto de tareas femeninas: sanidad, enseñanza, limpieza, etc., que llevan a que la mayoría de las mujeres ejerzan su actividad en un limitado número de empleos, normalmente relacionados con dicho concepto.

En sentido inverso, no suponen ni el $5 \%$ de la demanda en profesiones como albañil, electricista, conductor de camión, o pintor decorador de edificios.

De ello resulta que es en el sector servicios donde predominantemente realizan su trabajo las mujeres (el $79,73 \%$ ), quedando infrarrepresentadas en los otros sectores de actividad: un $12,78 \%$ en industria, un $6,23 \%$ en agricultura, y un $1,24 \%$ en la construcción. 
b) La discriminación de la contratación por sexo, ya que el porcentaje de las contrataciones por sexos no es acorde con la demanda, puesto que mientras que el $52,68 \%$ de los demandantes de empleo eran mujeres, los contratos de éstas sólo supusieron el $37,80 \%$ del total. Observando las características de las ocupaciones con mayor número de personas contratadas, hay casos en que se establece una discordancia entre los demandantes y los contratados en perjuicio de las mujeres, en el sentido de que existiendo mayor porcentaje de demandantes femeninas, los contratos se han dado a un porcentaje muy superior de hombres, este es el caso por ejemplo del trabajador agrícola (52\% de mujeres demandantes y el $64,4 \%$ de los contratos a hombres); dependiente de comercio al por menor (frente al $85,3 \%$ de las demandas femeninas sólo han obtenido el $67.7 \%$ de los contratos); mozo-mujer de limpieza (95,5\% de la demanda y el $81,6 \%$ de los contratos); cocinero $(61,8 \%$ de la demanda y el $51,22 \%$ de los contratos); profesor de educación general básica $(84,7 \%$ de la demanda y $66,01 \%$ de los contratos); médico $(64,8 \%$ de la demanda y $55,3 \%$ de los contratos); o pinche de cocina ( $79,7 \%$ de la demanda y $62,9 \%$ de los contratos). Como podemos ver, esta situación se produce en toda la gama de los niveles de estudios.

Este resultado plantea el interrogante de la existencia de una discriminación indirecta (ya que la discriminación directa queda resuelta legalmente) a través de mecanismos del mercado de trabajo que pesan de forma diferente sobre hombres y mujeres. Esta noción de discriminación indirecta es compleja en la medida en que supone procesos que parten de situaciones aparentemente neutras y conducen a resultados aparentemente neutros. Así, determinados requisitos profesionales de acceso a un puesto de trabajo impuestos por el empleador, o las condiciones del empleo que tienen un impacto negativo desproporcionado sobre las personas de un sexo o de un estado familiar determinado, son ejemplos que llevan a estas situaciones. Así, por ejemplo, aspectos como la atención a la familia supone una menor movilidad y flexibilidad laboral, tanto geográfica como horaria, y una disponibilidad laboral inferior a la de los hombres, sobre todo en el caso de los ejecutivos a los que las empresas exigen una dedicación incondicional.

Los salarios siguen la misma tónica discriminatoria. Si observamos los gráficos $n^{\circ} 6$ y 7 , según el nivel de estudios realizados, las mujeres tienen unos sueldos medios inferiores a los hombres en todos los casos, con valores que oscilan entre el $31,5 \%$ y el $43,3 \%$ menos; y lo mismo ocurre si comparamos los salarios según los grupos profesionales, en todos los casos, excepto construcción (donde su representación es mínima), son menores, oscilando entre el $20,2 \%$ y el $38,9 \%$. 
Cuadro 3. Índice de representación femenina de las ocupaciones que han tenido más contrataciones en 1996.

\begin{tabular}{|c|c|c|c|c|}
\hline Ocupaciones & (1) & (2) & (3) & (4) \\
\hline Trabajador agrícola & 12.43 & 52.0 & 0.29 & 0.35 \\
\hline Peón & 11.20 & 38.2 & 0.17 & 0.22 \\
\hline Albañil & 6.49 & 0.8 & 0.008 & 0.01 \\
\hline Empleado administrativo & 5.94 & 74.9 & 0.67 & 0.68 \\
\hline Dependiente comercio & 5.84 & 85.3 & 0.66 & 0.67 \\
\hline Camarero & 5.25 & 32.5 & 0.33 & 0.37 \\
\hline Mozo-mujer limpieza & 5.12 & 95.5 & 0.83 & 0.81 \\
\hline Peón construcción & 3.98 & 1.2 & 0.02 & 0.09 \\
\hline Cargador almacén & 1.75 & 7.7 & & 0.16 \\
\hline Cocinero & 1.41 & 61.8 & 0.53 & 0.51 \\
\hline Conductor camión & 1.37 & 0.7 & 0.007 & 0.01 \\
\hline Auxiliar clínica & 1.15 & 92.2 & 0.87 & 0.86 \\
\hline Peón ind. alimentarias & 1.15 & 76.5 & 0.46 & 0.62 \\
\hline Peón siderometalurgia & 0.90 & 23.7 & 0.06 & 0.12 \\
\hline ATS & 0.87 & 85.1 & 0.78 & 0.83 \\
\hline Electricista & 0.87 & 1.2 & 0.01 & 0.02 \\
\hline Repartidor a domicilio & 0.82 & 6.1 & 0.08 & 0.20 \\
\hline Camarero/a-hostelería & 0.77 & 98.2 & 0.95 & 0.94 \\
\hline Cajero comercio & 0.72 & 82.4 & 0.88 & 0.89 \\
\hline Profesor EGB & 0.71 & 84.7 & 0.69 & 0.66 \\
\hline Vigilante & 0.59 & 14.6 & 0.06 & 0.16 \\
\hline Cosedor máquina industrial & 0.58 & 97.8 & 0.91 & 0.91 \\
\hline Estibador & 0.56 & 2.4 & & 0.005 \\
\hline Médico medicina general & 0.54 & 64.8 & & 0.55 \\
\hline Agente de comercio & 0.54 & 16.1 & & 0.34 \\
\hline Encofrador & 0.54 & 0.3 & 0.009 & 0.005 \\
\hline Cartero & 0.53 & 67.0 & & 0.58 \\
\hline Entrevistador & 0.51 & 65.7 & & 0.69 \\
\hline Pintor decorador edificios & 0.48 & 2.2 & & 0.01 \\
\hline Carpintero & 0.47 & 5.5 & 0.05 & 0.04 \\
\hline Embalador a mano & 0.44 & 82.2 & 0.84 & 0.81 \\
\hline Azafata de información & 0.43 & 96.4 & & 0.91 \\
\hline Telefonista & 0.39 & 93.1 & & 0.85 \\
\hline TOTAL & 75.34 & - & & - \\
\hline
\end{tabular}

(1) Porcentaje de contratación respecto al total de contratos realizados. (2) Porcentaje de demanda femenina en cada ocupación. (3) Índice de representación femenina en cada ocupación en 1992. (4) Índice de representación femenina en cada ocupación en 1996.

Fuente: INEM. Observatorio ocupacional. Elaboración propia.

La situación profesional va mejorando aunque todavia las mujeres representan el $60,2 \%$ de los trabajos de ayuda familiar (lo que está demostrando una elevada dependencia social), ocupan un $44 \%$ del empleo en el 
sector público, un $33 \%$ de los asalariados del sector privado, un $28,1 \%$ de los miembros de cooperativas, y sólo un $26,28 \%$ del total de empresarios. Por otro lado, la marginalidad es otra característica de un buen número de mujeres que tienen algún trabajo pero que con frecuencia son oficialmente inactivas. La cifra de ocupados marginales estimados por la EPA tiene un elevado porcentaje en las mujeres, y, según la encuesta de condiciones de vida y trabajo, una de cada tres mujeres ocupadas está en situación irregular.

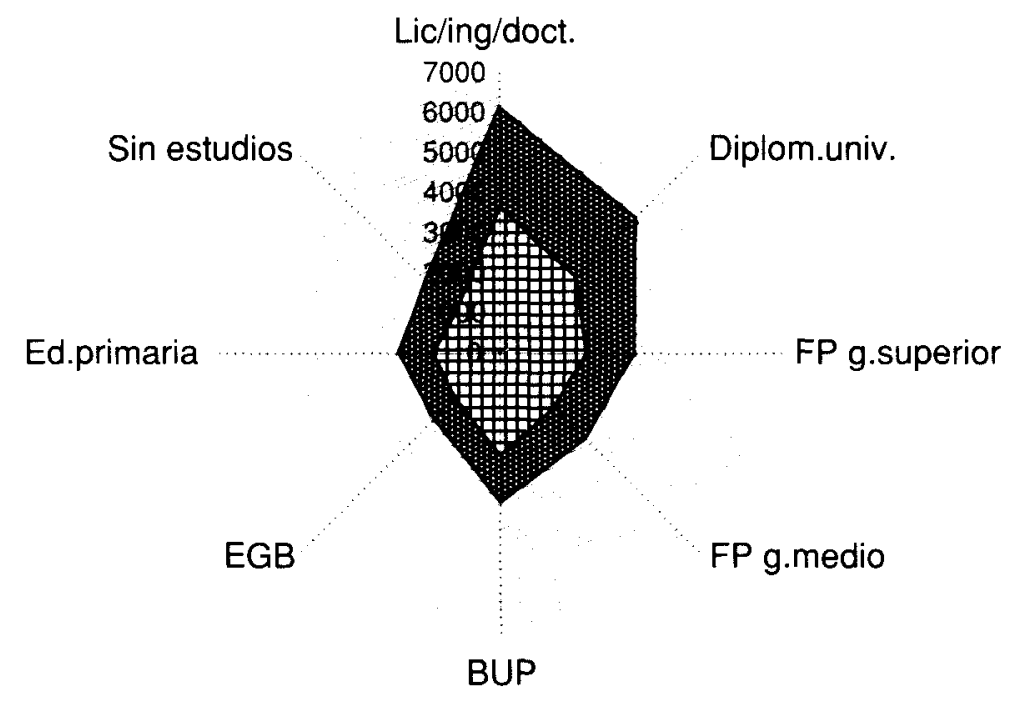

Dhombres Emujeres

Gráfico 6. Sueldo anual por trabajador según nivel de estudios.

En definitiva, para que las mujeres cuenten realmente con una igualdad de oportunidades, además de perfeccionar y completar el desarrollo normativo del principio de igualdad, hace falta seguir desarrollando actitudes, comportamientos y estructuras sociales que permitan a las mujeres su participación activa en todos los campos de la actividad económica, política y social.

Teniendo en cuenta las caracteristicas de la mujer activa mencionadas hasta aqui, podríamos diferenciar dos grupos: el de las «mujeres cualificadas» y el de las «mujeres sin cualificar», subdividiéndose este último 


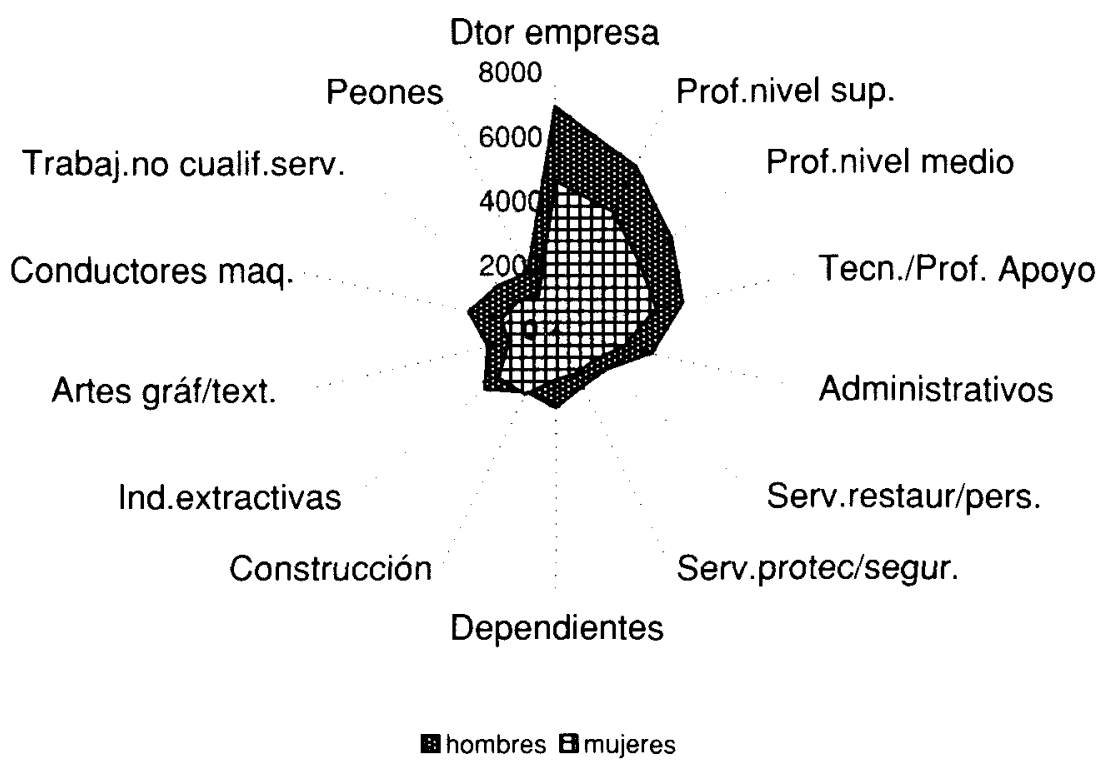

Gráfico 7. Sueldo anual por trabajador según grupos profesionales.

grupo entre jóvenes y mujeres de mayor edad. Las mujeres cualificadas con un nivel profesional medio o medio- alto representan la mano de obra femenina con mayor continuidad y estabilidad dentro del mercado de trabajo, afectándole en menor grado su estado civil. Este tipo es el que está modificando las tendencias de la actividad femenina en los últimos años, siendo el grupo que ha experimentado un mayor crecimiento, aunque sigue siendo un grupo en minoría y centrado en un reducido número de ocupaciones del sector servicios, de tipo tradicional, como son la sanidad, la educación y el sector público.

Las mujeres jóvenes sin cualificar suponen el grupo mayoritario dentro de la población activa femenina y su baja preparación les lleva a ocupar puestos poco cualificados del sector industrial o de los servicios. Las mujeres de edad relativamente alta sin cualificar suponen en torno al $25 \%$, acceden al trabajo de forma temporal para obtener una ayuda familiar, y en algunos casos trabajan como autónomos en la agricultura, en el comercio, o en la hostelería. En ambos casos, el estado civil y el nivel económico tienen una gran incidencia sobre su situación de actividad o inactividad. 


\section{DIFERENCIACIÓN ESPACIAL DE LA ACTIVIDAD E INACTIVIDAD FEMENINA.}

La heterogeneidad en la propensión al trabajo de la mujer como resultado de sus características de edad, estado civil, nivel cultural, social, económico, incluso según la profesión de su marido en las mujeres casadas, tiene diferente incidencia en las distintas regiones, produciéndose una localización geográfica desigual de la situación laboral femenina en nuestro país.

Las propias diferencias regionales en las condiciones de producción y en el ritmo de cambio social, se traducen en diferencias sensibles en los valores relacionados con la posición social de la mujer y con su trabajo intra y extradoméstico, determinando en gran manera su conducta. La ideología de años atrás, que defendía la familia y el mantenimiento de la mujer casada en el hogar, ha cambiado de forma general aunque en distinto grado.

La población inactiva femenina, según podemos ver en los mapas de distribución de la inactividad, alcanza tasas muy elevadas en las provincias del interior, superando el $70 \%$ en provincias como Zamora, Ávila, Ciudad Real, Guadalajara, Cuenca y Teruel. Por el contrario, Gerona y Lugo son las provincias con menor tasa de inactividad femenina, provincias en las que es de destacar en este año la contratación de mujeres con estudios superiores en número muy superior al de hombres. En el caso de Gerona estas contrataciones se enmarcan dentro del sector servicios, en contratos de administración y comercio, actividades que coinciden con su contexto económico; mientras que en el caso de Lugo, provincia eminentemente agrícola, es de destacar la contratación de mujeres en la sanidad y en la administración.

El contraste mayor entre la inactividad masculina y femenina se produce en las provincias de Zamora (donde en ambos casos hay una alta tasa de inactividad), y en Valladolid, Toledo, Ciudad Real y Cádiz donde esta tasa tiene sentido contrario para los dos sexos.

Relacionando las tasas de actividad, empleo y paro por Comunidades Autónomas y por provincias, que puede apreciarse en los mapas de población activa femenina, con la media nacional en ambos sexos, se corrobora la situación laboral de la mujer descrita en anteriores apartados:

- En todos los grupos de edad y en todas las Comunidades Autónomas, en 1996 continua la situación de años anteriores: el porcentaje de población masculina ocupada es mayor que el de la femenina. La diferencia más baja entre ambas se da en los menores de 25 años, con 19 
Distribución de la diferencia de inactividad entre sexos (Año 1996)

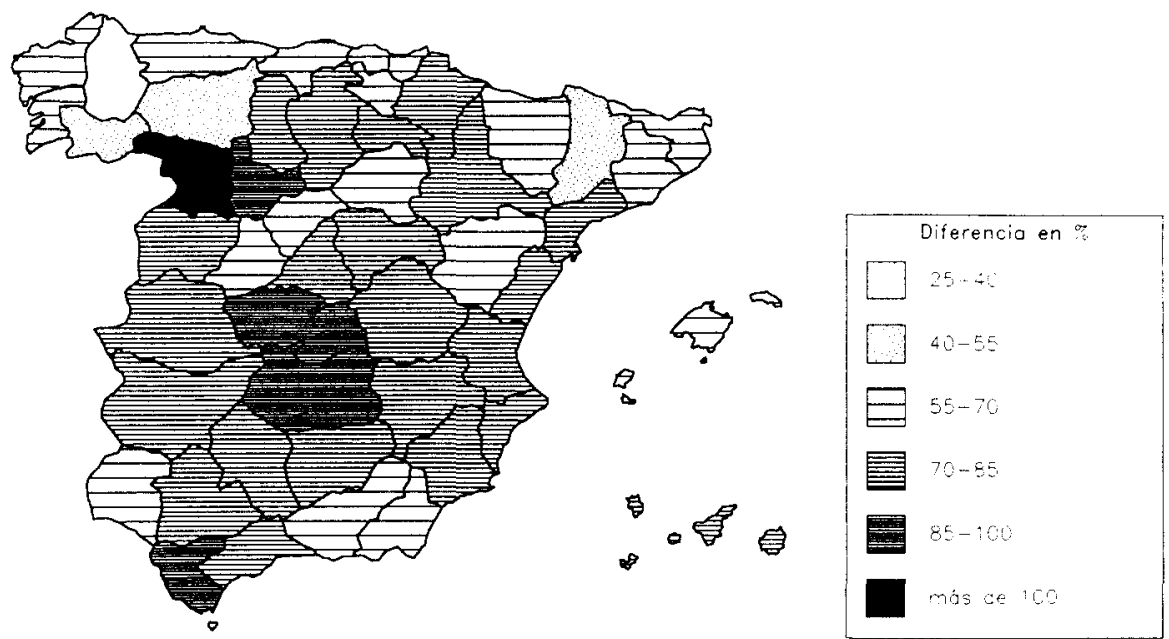

Distribución de la población inactiva femenina (Año 1996)

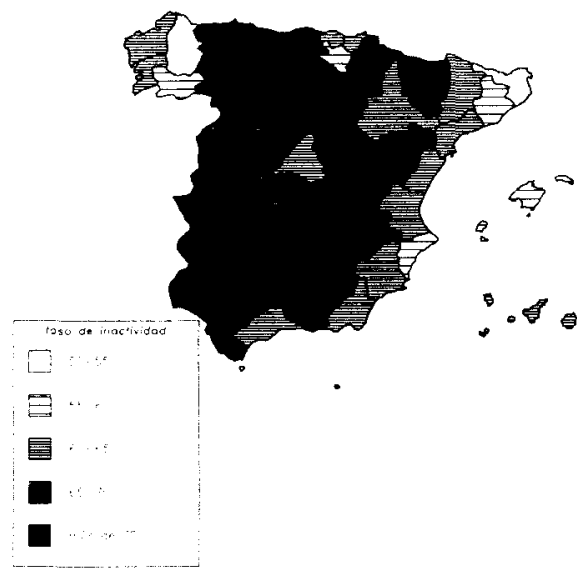

Distribución de la población inactiva masculina (Año 1996) 
La incorporación al mercado laboral de la mujer inactiva: su distribución en España...

Distribución de la población activa femenina (Año 1996)

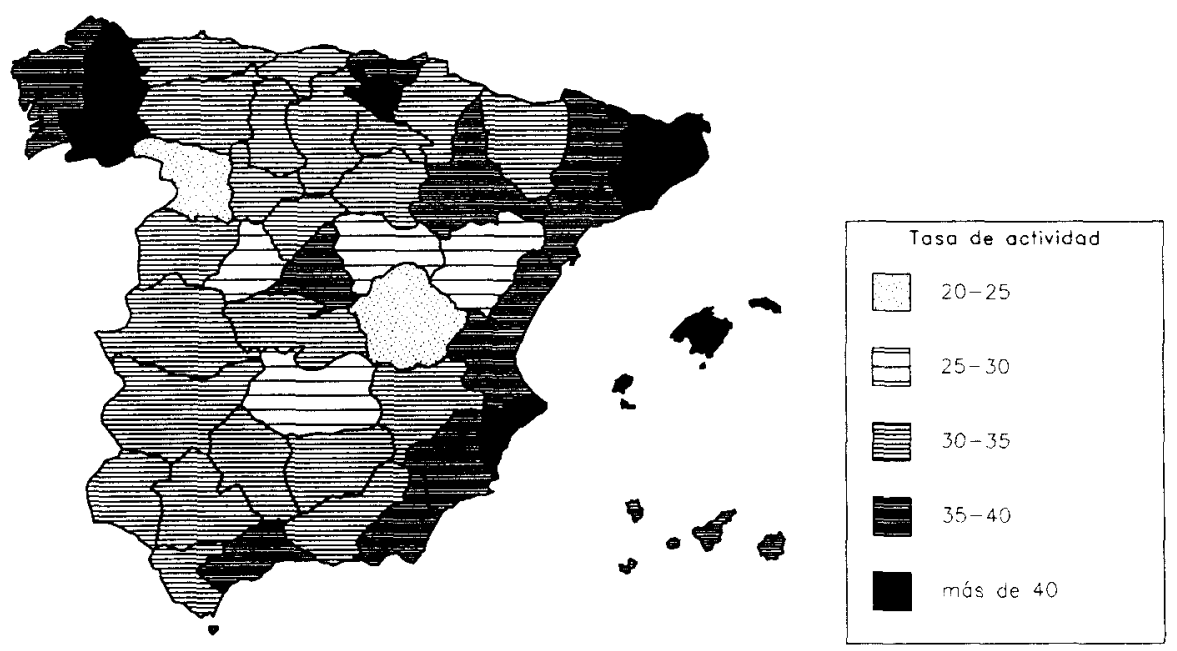

Distribución de la población femenina en paro (Año 1996)

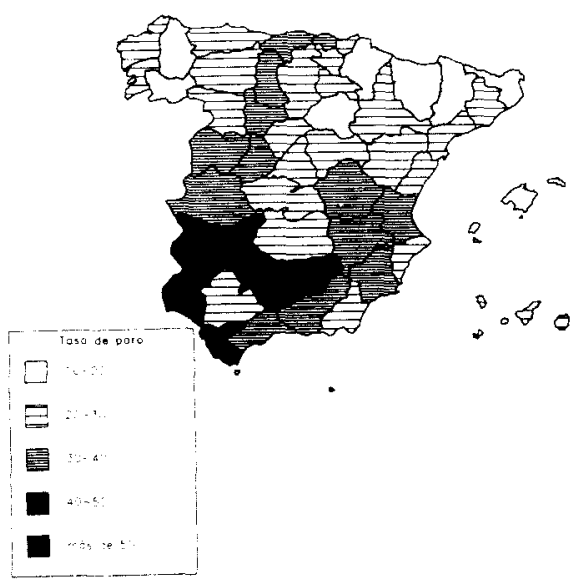

Distribución del empleo femenino

(Año 1996)

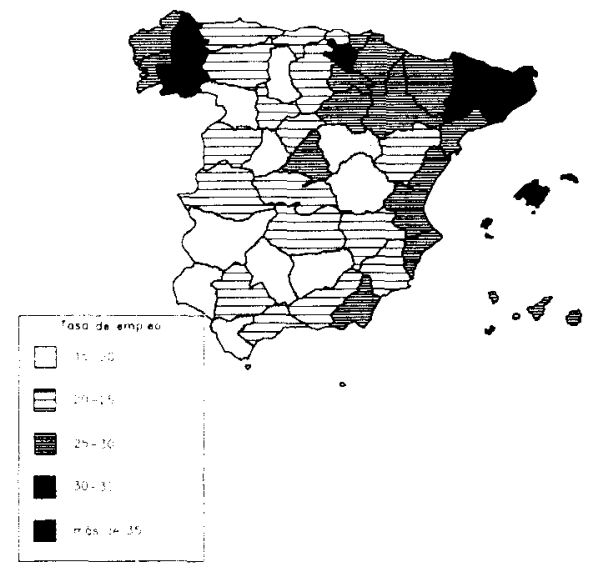


puntos porcentuales a favor de los hombres. La menor diferencia en la ocupación entre hombres y mujeres se da en Galicia (39\% de mujeres y $61 \%$ de hombres) mientras que la mayor diferencia se produce en Extremadura, con una diferencia entre ambos de un $41 \%$.

- En ninguna provincia la tasa de actividad femenina alcanza la media nacional total, y la tasa de empleo femenino sólo supera la media nacional en Gerona, en cambio, el paro femenino supera la media nacional en el $78 \%$ de las provincias, quedando sólo el paro por debajo en Lérida (13.4), Soria (15.1) Gerona (16.6), Navarra (17.9), Baleares (18.5), Lugo (18.5), Orense (19.6), Huesca (19.6), Castellón (20.5), Tarragona (20.7), y La Rioja (21.2).

- En la distribución de la actividad femenina podriamos hablar de un predominio de la periferia Este y Norte (ver mapas), que en unos casos es coincidente con la tendencia de la tasa de actividad media nacional y en otras adquieren una significativa matización. Entre las Comunidades que desde 1993 a 1996 se mantienen por encima de la tasa nacional de actividad, las islas Baleares presentan la mayor tasa de actividad a lo largo de todo este período de tiempo, con unos 4 puntos por encima de la nacional, y es la tercera provincia tanto en cuanto a población activa femenina como de empleo femenino, quedando la posición de la actividad y empleo masculino en décimo y cuarto lugar respectivamente.

Cataluña sigue a Baleares con cerca de 3,5 puntos por encima de la media nacional y también presenta una alta tasa de actividad femenina, no en vano Gerona ocupa el primer lugar tanto en actividad como en empleo femenino, y Barcelona y Tarragona el séptimo y octavo lugar del empleo femenino respectivamente. Lo mismo podemos decir de la Comunidad de Madrid, que ha tenido una tendencia positiva de crecimiento de 3,2 puntos respecto a 1993, superando también su tasa de actividad y empleo la media nacional.

La Comunidad Valenciana, pese a experimentar un descenso de la actividad en 1996 respecto a 1993, sigue por encima de la media nacional en todas sus provincias, quedando Valencia, en relación con el empleo, por debajo de la media femenina.

Galicia, comunidad donde tiene gran peso la agricultura, pese a que presenta en 1996 un descenso en su tasa de actividad respecto a 1993, es una Comunidad que tiene gran importancia en el empleo femenino, pues excepto en La Coruña, donde la tasa de actividad femenina queda por debajo de la media nacional, aunque no su empleo, las demás provincias superan esa media tanto en actividad como en empleo, es más, Lugo es la segunda provincia española en cuanto a actividad y empleo femenino, y Orense la sexta y cuarta respectivamente. 
Finalmente, en el País Vasco, Álava ocupa un puesto destacado en cuanto a actividad y empleo femenino se refiere, lo mismo que Guipúzcoa, no así Vizcaya que queda algo por debajo de la media nacional.

Analizando las situaciones de empleo y paro dentro de esta población activa, se puede establecer, a grandes rasgos, una clara diferenciación entre el Nor-noreste y el sur. Si bien el paro femenino es superior al masculino en todas las provincias, destaca especialmente en la mitad sur del país. Las tasas más altas del paro femenino siguen la distribución del paro en general, situado espacialmente y con valores superiores a la media en Andalucia $(31,9 \%)$, Extremadura $(30,8 \%)$, Ceuta y Melilla $(29,08 \%)$, destacando también algunas provincias de Castilla-León y Castilla-La Mancha. Navarra permanece con la tasa más baja de paro durante todos estos años, situándose en 1996 en algo más de 10 puntos por debajo de la nacional, y Baleares resulta ser la segunda Comunidad del territorio con menor tasa de paro.

Reforzando esta situación, la economía irregular tiene mayor incidencia en las comunidades que presentan mayores tasas de paro, mayor peso relativo de la agricultura, mayor presencia de la industria manufacturera y de bienes de consumo, mayor incidencia turística, y menores niveles de población activa oficial. Por el contrario, muestra menor incidencia en Comunidades que presentan mayor concentración industrial y mayor presencia del sector público. Las Comunidades que presentaban un porcentaje de empleo irregular sobre el total de la ocupación, superior al $25 \%$, eran Murcia $(>35 \%)$, Castilla-La Mancha $(>35 \%)$, Andalucía $(>35 \%)$, Extremadura ( $>30 \%$ ), Galicia ( $>30 \%$ ), País Vasco, Cataluña, Canarias, y Castilla-León.

- Por sectores económicos, más del $61 \%$ de los ocupados están en el sector servicios, con un $45,4 \%$ de mujeres en él. En 1996, el 48,5\% de los ocupados en este sector se concentraban en las Comunidades Autónomas de Cataluña (16,8\%), Madrid (15,9\%), y Andalucía (15,7\%). Entre las provincias que destacan en este sector, en números absolutos, las mujeres ocupadas en servicios son superiores a los hombres en todas las provincias catalanas y en Almería, y, además, en todo el País Vasco, Baleares, Valencia, Castellón, Cantabria, Navarra, La Riaja, Huesca, y Orense.

- En la industria, la mujer activa supone un 25,9\%, destacando en las provincias de Barcelona, Madrid, Alicante y Valencia. En el sector agrario, donde supone el $32,06 \%$ de la población activa, tiene su mayor representación en Galicia, donde ocupa el 50,67\% del sector, y en Andalucía el $37,32 \%$, en la Comunidad Valenciana el $19,8 \%$ y en Castilla-León igualmente el $19,8 \%$. 
- El sector de la construcción, donde tiene muy baja representación la mujer (un 5,8\% del total nacional) es prioritario en Barcelona, Madrid, donde alcanza la mayor representación, y Valencia.

- Si se analizan las contrataciones, según la información del INEM, en 1996, a escala nacional, las mujeres representan sólo el $37,8 \%$ de éstas. Las Comunidades que presentan unos índices en contratación de mujeres superiores a la media nacional son las de Aragón, Cataluña, Madrid, País Vasco y Navarra, siendo esta última la que ocupa el primer puesto; Comunidades que no son precisamente las que han tenido un crecimiento mayor de contrataciones entre 1993 y 1996 -Andalucia $(130,4 \%)$, Extremadura $(106,5 \%)$, País Vasco $(98,5 \%)$ y Murcia $(90,8 \%)$ - Esto no resulta relevante si tenemos en cuenta que precisamente Andalucía, Extremadura y Baleares son las Comunidades que realizan mayor número de contratos eventuales.

En contraposición, los porcentajes más bajos de contratación de mujeres se registran en Extremadura, Melilla, Andalucía, Castilla-La Mancha y Ceuta, coincidentes sólo en un caso con las Comunidades que han experimentado un crecimiento menor: Ceuta $(38,2 \%)$, Castilla-La Mancha $(52,6 \%)$ y Navarra $(58,1 \%)$. En estas Comunidades, además, los contratos por obra y servicio son mayoritarios (Castilla-La Mancha, Melilla, Asturias, Castilla- León, Galicia y Madrid con niveles superiores al 32\%); y los contratos a tiempo parcial tienen bastante importancia en Melilla y Madrid con un $23,7 \%$ y un $23,2 \%$ respectivamente. Los contratos de interinidad destacan en Ceuta y País Vasco con el $15,7 \%$ y $12,3 \%$ respectivamente).

Según puede apreciarse en el cuadro $n^{\circ} 4$, es generalizado el incremento de los contratos realizados a mujeres en todas las provincias, aunque no debemos olvidar en estas cifras que ocho de cada diez contratos son eventuales por circunstancias de la producción, de obra y servicio, o contratos a tiempo parcial, contratos que tienen la mayor representatividad entre todos los realizados, ya que suponen el $80,2 \%$ del total. En resumen, si bien el incremento de los contratos es una constante, hay que tener en cuenta que un elevado número consiste en contratos de condiciones poco estables. Por ejemplo, Andalucía que es la Comunidad que más ha incrementado su número de contratos, en un 130,4\%, ha realizado en 1996 una contratación eventual y a tiempo parcial del $54,8 \%$; lo mismo ocurre con Extremadura, cuyo incremento ha sido del $106,5 \%$ pero que sus contratos eventuales $y$ parciales suponen el $54,3 \%$ de la contratación; igualmente, Madrid, que aunque sólo ha subido un $70,6 \%$ sus contratos es la tercera Comunidad en volumen de contratación, tiene entre contratos eventuales, de obra y servicio y a tiempo parcial el 76\% de los contratos realizados en el año 1996. 
Población femenina activa en el sector agrario (Año 1996)

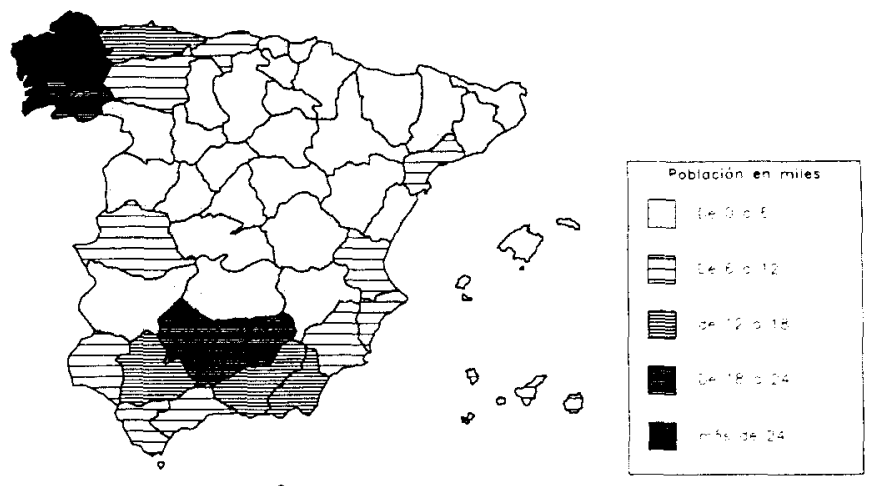

Población activa femenina en el sector industrial (Año 1996)

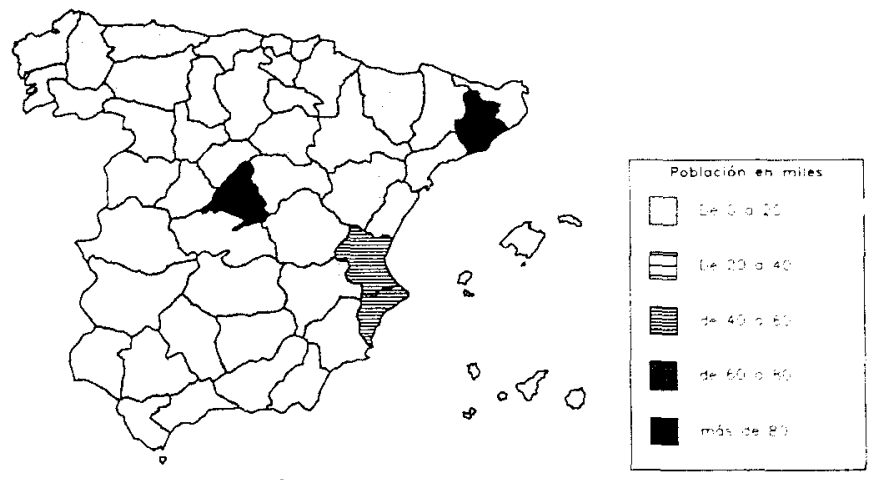

Población activa femenina en el sector servicios (Año 1996)

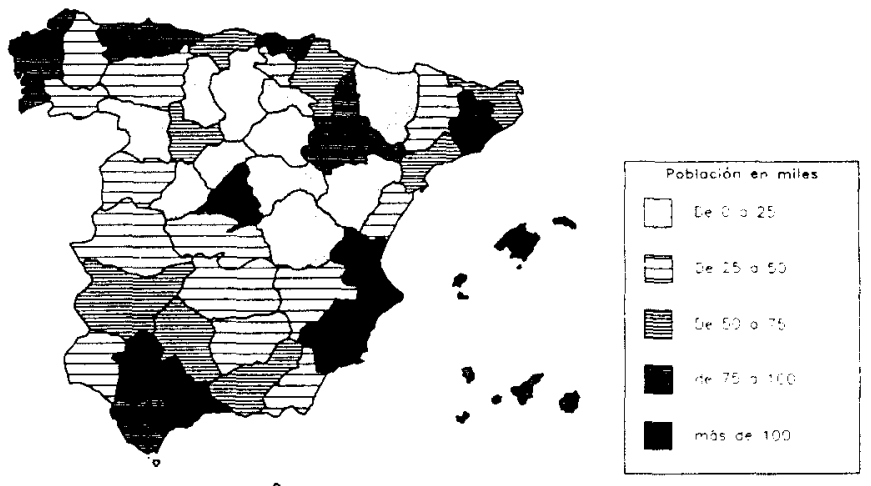


Cuadro 4. Porcentaje de mujeres demandantes de empleo (1) $y$ de mujeres contratadas (2)

\begin{tabular}{|c|c|c|c|c|c|c|}
\hline & $\begin{array}{c}1992 \\
\text { (1) }\end{array}$ & (2) & $\begin{array}{c}1994 \\
(1)\end{array}$ & (2) & $\begin{array}{c}1996 \\
\text { (1) }\end{array}$ & (2) \\
\hline \multicolumn{7}{|l|}{ ANDALUCÍA } \\
\hline Almería & 51.05 & 32.20 & 49.64 & 39.66 & 50.62 & 39.88 \\
\hline Cádiz & 45.80 & 22.83 & 45.37 & 24.05 & 45.37 & 25.38 \\
\hline Córdoba & 54.96 & 25.46 & 54.91 & 36.08 & 54.09 & 39.86 \\
\hline Granada & 53.28 & 27.02 & 51.71 & 32.92 & 50.88 & 36.78 \\
\hline Huelva & 52.18 & 13.69 & 51.24 & 37.08 & 51.17 & 36.66 \\
\hline Jaén & 47.75 & 22.09 & 52.84 & 23.87 & 52.40 & 31.73 \\
\hline Málaga & 48.87 & 33.80 & 48.32 & 36.06 & 48.99 & 36.66 \\
\hline $\begin{array}{l}\text { Sevilla } \\
\text { ARAGÓN }\end{array}$ & 54.55 & 24.86 & 52.70 & 33.75 & 52.53 & 34.62 \\
\hline Huesca & 58.70 & 41.67 & 59.22 & 38.42 & 59.09 & 42.64 \\
\hline Teruel & 55.43 & 30.75 & 56.25 & 32.71 & 58.00 & 37.89 \\
\hline Zaragoza & 58.53 & 40.68 & 57.28 & 39.80 & 59.67 & 41.89 \\
\hline ASTURIAS & 58.21 & 33.27 & 53.57 & 36.24 & 53.94 & 38.55 \\
\hline $\begin{array}{l}\text { BALEARES } \\
\text { C.-LA MANC }\end{array}$ & 53.59 & 40.34 & 54.29 & 41.50 & 55.62 & 42.40 \\
\hline Albacete & 51.07 & 30.41 & 49.77 & 30.63 & 50.96 & 31.95 \\
\hline Ciudad Real & 46.19 & 24.37 & 45.66 & 24.34 & 45.94 & 25.47 \\
\hline Cuenca & 49.62 & 25.57 & 47.54 & 29.37 & 48.68 & 33.63 \\
\hline Guadalajara & 57.06 & 31.14 & 54.66 & 28.88 & 55.51 & 32.37 \\
\hline $\begin{array}{l}\text { Toledo } \\
\text { CASTILLA-LI }\end{array}$ & 51.55 & 27.06 & 50.14 & 29.27 & 50.92 & 33.43 \\
\hline Ávila & 54.74 & 22.72 & 52.44 & 30.44 & 53.24 & 32.26 \\
\hline Burgos & 56.41 & 31.51 & 56.00 & 36.03 & 58.03 & 41.24 \\
\hline León & 53.14 & 27.10 & 53.58 & 30.77 & 56.12 & 33.74 \\
\hline Palencia & 54.24 & 32.12 & 53.94 & 37.13 & 54.79 & 40.47 \\
\hline Salamanca & 56.73 & 27.45 & 55.74 & 31.62 & 55.81 & 36.27 \\
\hline Segovia & 59.46 & 32.12 & 59.98 & 38.30 & 59.82 & 41.99 \\
\hline Soria & 58.92 & 29.92 & 57.71 & 40.71 & 61.37 & 43.34 \\
\hline Valladolid & 56.61 & 31.91 & 54.49 & 35.58 & 55.65 & 36.80 \\
\hline \multicolumn{7}{|l|}{ CANARIAS } \\
\hline Las Palmas & 50.04 & 40.09 & 50.41 & 39.28 & 53.21 & 38.97 \\
\hline Tenerife & 48.95 & 36.40 & 49.03 & 39.84 & 51.37 & 38.70 \\
\hline CANTABRIA & 48.87 & 35.65 & 49.61 & 35.99 & 48.05 & 35.73 \\
\hline \multicolumn{7}{|l|}{ CATALUÑA } \\
\hline Barcelona & 53.94 & & 51.24 & 41.29 & 53.28 & 43.50 \\
\hline Gerona & 54.97 & 42.76 & 53.93 & 43.59 & 54.95 & 44.26 \\
\hline Lérida & 59.79 & 39.74 & 56.14 & 40.74 & 56.59 & 41.44 \\
\hline $\begin{array}{l}\text { Tarragona } \\
\text { C. VALENCl }\end{array}$ & 52.00 & 37.19 & 50.36 & 37.23 & 52.36 & 39.12 \\
\hline Alicante & 50.78 & 37.94 & 50.11 & 37.58 & 50.93 & 38.19 \\
\hline
\end{tabular}


Cuadro 4. Porcentaje de mujeres demandantes de empleo (1) $y$ de mujeres contratadas (2) (continuación)

\begin{tabular}{lcccccc}
\hline & $\begin{array}{c}1992 \\
(1)\end{array}$ & $(2)$ & $\begin{array}{c}1994 \\
(1)\end{array}$ & $(2)$ & $\begin{array}{c}1996 \\
(1)\end{array}$ & $(2)$ \\
\hline Castellón & 55.00 & 34.95 & 56.60 & 35.88 & 56.65 & 38.91 \\
Valencia & 55.91 & 35.17 & 54.69 & 35.73 & 56.06 & 37.57 \\
EXTREMADURA & & & & & & \\
Badajoz & 45.79 & 26.27 & 44.97 & 23.48 & 44.96 & 24.58 \\
Cáceres & 49.01 & 28.22 & 47.13 & 29.82 & 46.78 & 33.42 \\
GALICIA & & & & & & \\
Coruña, La & 53.08 & 31.44 & 50.39 & 35.29 & 51.00 & 38.59 \\
Lugo & 51.75 & 26.35 & 50.02 & 28.44 & 50.37 & 43.84 \\
Orense & 50.18 & 20.64 & 51.03 & 31.71 & 51.51 & 35.61 \\
Pontevedra & 54.87 & 32.95 & 52.65 & 36.94 & 54.64 & 38.88 \\
MADRID & 59.04 & 38.71 & 54.53 & 38.71 & 55.03 & 39.52 \\
NAVARRA & 60.17 & 43.66 & 59.80 & 41.33 & 59.67 & 43.13 \\
PAíS VASCO & & & & & & \\
Álava & 57.51 & 43.19 & 56.80 & 43.22 & 59.46 & 43.17 \\
Guipúzcoa & 50.84 & 39.57 & 51.41 & 44.18 & 55.88 & 43.87 \\
Vizcaya & 50.07 & 37.07 & 48.33 & 37.75 & 50.81 & 37.72 \\
RIOJA, LA & 58.39 & 34.29 & 58.52 & 37.73 & 59.47 & 38.14 \\
CEUTA & 47.44 & 34.41 & 46.99 & 32.82 & 47.41 & 35.10 \\
MELILLA & 60.11 & 31.58 & 59.96 & 26.55 & 58.61 & 28.72 \\
\hline
\end{tabular}

Fuente: INEM. Elaboración propia.

Igualmente interesante resulta el análisis del nivel de estudios entre mujeres demandantes de empleo y contratadas, que muestra el cuadro $n^{\circ}$ $5 \mathrm{El}$ predominio en ambos casos es de estudios de nivel medio y lo más habitual es que coincida a más demanda de un nivel más contratos de dicho nivel, o que, aún habiendo mayor demanda de estudios superiores, la mayoría de los contratos queden en nivel inferior, no obstante hay casos en que no se da esta relación como ocurre en Asturias, Salamanca, y Soria, en los que pese a una demanda mayor de estudios medios se correspondió una mayor contratación en estudios superiores. Soria es el caso más espectacular, pues el $19,25 \%$ de los contratos a mujeres se hicieron a aquellas que tenían estudios superiores, especialmente en el área de sanidad ( 1.320 médicos y 1.063 ATS) en calidad de "otros contratos no especificados". En Salamanca se centró en empleados administrativos (1.712 mujeres) en calidad de "parcial determinado con prestación y reducción de jornada", lo mismo que en Asturias.

La distribución de la población femenina demandante de empleo a través del INEM en 1996 con mayor nivel de estudios — nivel superior y medio- 
muestra diferencias regionales notables, que van desde el $43,3 \%$ de las Baleares hasta el $23,81 \%$ de Soria, superándose el $15 \%$ en Salamanca $(21,9 \%)$, Segovia $(19,8 \%)$, Valladolid $(18,5 \%)$, Navarra $(17,6 \%)$, Huesca $(17,6 \%)$, Palencia $(16,7 \%)$, Vizcaya $(16 \%)$, Teruel $(15,8 \%)$, Madrid $(15,4 \%)$ Burgos (15,3\%), Ávila (15,1\%), y Guipúzcoa (15\%). Estas provincias, debido a esta mayor instrucción de la mujer, deberían tener menor tasa de paro y mayor de empleo femenino, y aunque así es en la mayoría no lo es en su totalidad, como son los casos de Salamanca, Valladolid, Vizcaya, y Ávila.

Según la edad, los contratados menores de 25 años alcanzan los porcentajes más altos en Aragón, Baleares, Cataluña, Madrid, Murcia, Navarra y la Rioja, en donde superan el $37 \%$. Por el contrario Andalucía, Asturias, Extremadura y Ceuta no suponen el $29 \%$. Los contratos entre 25 y 45 años tienen especial relevancia en Extremadura y Andalucia, en donde alcanzan el $15,7 \%$ y el $14,7 \%$ respectivamente, en ambos casos a costa del grupo de los más jóvenes. Del resto de las Comunidades sólo Castilla-La Mancha (12,6\%), Comunidad Valenciana (11,6\%) y Galicia $(11,5 \%)$ superan la media nacional.

Cuadro 5. Nivel de estudios de las mujeres demandantes/contratadas en empleos a través del INEM

\begin{tabular}{lccc}
\hline & E. superiores & E. medios & índice $E$ \\
\hline ANDALUCíA & & & \\
Almería & $4.07 / 2.40$ & $5.91 / 4.42$ & $1.14 / 1.09$ \\
Cádiz & $2.21 / 1.49$ & $4.70 / 3.85$ & $1.09 / 1.06$ \\
Córdoba & $2.48 / 1.62$ & $4.04 / 2.44$ & $1.08 / 0.99$ \\
Granada & $4.58 / 3.53$ & $5.81 / 4.93$ & $1.14 / 1.10$ \\
Huelva & $2.04 / 1.39$ & $3.91 / 2.55$ & $1.07 / 1.05$ \\
Jaén & $3.09 / 1.50$ & $5.27 / 3.06$ & $1.11 / 1.05$ \\
Málaga & $2.97 / 1.80$ & $4.22 / 3.72$ & $1.10 / 1.07$ \\
Sevilla & $3.56 / 1.97$ & $3.45 / 2.31$ & $1.10 / 1.06$ \\
ARAGÓN & & & \\
Huesca & $5.59 / 6.24$ & $12.08 / 9.37$ & $1.23 / 1.21$ \\
Teruel & $4.83 / 3.50$ & $10.98 / 6.92$ & $1.20 / 1.13$ \\
Zaragoza & $6.83 / 3.87$ & $8.62 / 5.99$ & $1.22 / 1.13$ \\
ASTURIAS & $6.48 / 7.08$ & $8.29 / 6.91$ & $1.21 / 1.21$ \\
BALEARES & $1.94 / 0.40$ & $2.39 / 1.35$ & $1.06 / 1.02$ \\
CANARIAS & & & \\
Las Palmas & $2.95 / 1.57$ & $4.38 / 2.78$ & $1.10 / 1.05$ \\
Tenerife & $3.99 / 2.56$ & $3.71 / 4.54$ & $1.11 / 1.09$ \\
C.-LA MANCHA & & & \\
Albacete & $3.42 / 2.03$ & $4.40 / 3.56$ & $1.11 / 1.07$ \\
Ciudad Real & $4.18 / 4.68$ & $4.88 / 7.49$ & $1.13 / 1.16$ \\
\hline
\end{tabular}


La incorporación al mercado laboral de la mujer inactiva: su distribución en España...

Cuadro 5. Nivel de estudios de las mujeres demandantes/contratadas en empleos a través del INEM (continuación)

\begin{tabular}{|c|c|c|c|}
\hline & E. superiores & E. medios & Índice $E$ \\
\hline Cuenca & $5.19 / 5.33$ & $8.10 / 8.10$ & $1.18 / 1.15$ \\
\hline Guadalajara & $7.55 / 4.77$ & $5.81 / 3.77$ & $1.20 / 1.13$ \\
\hline Toledo & $4.57 / 2.69$ & $4.08 / 3.17$ & $1.13 / 1.08$ \\
\hline \multicolumn{4}{|c|}{ CASTILLA-LEÓN } \\
\hline Ávila & $6.32 / 2.83$ & $8.82 / 4.62$ & $1.14 / 1.10$ \\
\hline Burgos & $6.16 / 4.04$ & $9.20 / 6.21$ & $1.21 / 1.14$ \\
\hline León & $5.62 / 4.25$ & $9.13 / 6.88$ & $1.20 / 1.15$ \\
\hline Palencia & $5.50 / 6.20$ & $11.24 / 8.60$ & $1.22 / 1.21$ \\
\hline Salamanca & $10.91 / 9.54$ & $11.01 / 8.18$ & $1.32 / 1.27$ \\
\hline Segovia & $11.29 / 4.25$ & $8.52 / 3.85$ & $1.31 / 1.12$ \\
\hline Soria & $8.31 / 19.25$ & $15.5 / 17.64$ & $1.32 / 1.51$ \\
\hline Valladolid & $8.83 / 4.82$ & $9.73 / 5.66$ & $1.27 / 1.15$ \\
\hline Zamora & $5.46 / 8.67$ & $8.46 / 11.48$ & $1.19 / 1.28$ \\
\hline CANTABRIA & $5.39 / 3.80$ & $7.88 / 5.19$ & $1.18 / 1.12$ \\
\hline \multicolumn{4}{|l|}{ CATALUÑA } \\
\hline Barcelona & $3.69 / 3.18$ & $3.24 / 6.02$ & $1.10 / 1.11$ \\
\hline Gerona & $2.26 / 2.39$ & $2.74 / 3.73$ & $1.07 / 1.08$ \\
\hline Lérida & $4.09 / 3.29$ & $7.19 / 7.69$ & $1.15 / 1.14$ \\
\hline Tarragona & $2.49 / 3.05$ & $3.45 / 6.49$ & $1.08 / 1.12$ \\
\hline \multicolumn{4}{|c|}{ C. VALENCIANA } \\
\hline Alicante & $3.33 / 1.61$ & $3.81 / 2.29$ & $1.10 / 0.97$ \\
\hline Castellón & $5.53 / 2.86$ & $5.25 / 3.54$ & $1.16 / 1.09$ \\
\hline Valencia & $5.36 / 2.69$ & $5.20 / 3.67$ & $1.15 / 1.09$ \\
\hline \multicolumn{4}{|c|}{ EXTREMADURA } \\
\hline Badajoz & $2.77 / 0.89$ & $5.61 / 3.37$ & $1.11 / 1.04$ \\
\hline Cáceres & $7.38 / 7.11$ & $6.09 / 5.41$ & $1.20 / 1.19$ \\
\hline Lugo & $5.24 / 8.44$ & $7.15 / 20.47$ & $1.17 / 1.37$ \\
\hline Orense & $4.27 / 6.75$ & $5.23 / 8.94$ & $1.13 / 1.22$ \\
\hline Pontevedra & $3.99 / 4.79$ & $4.76 / 6.47$ & $1.13 / 1.05$ \\
\hline MADRID & $10.12 / 4.32$ & $5.32 / 3.22$ & $1.25 / 1.11$ \\
\hline MURCIA & $4.96 / 1.84$ & $6.33 / 4.54$ & $1.03 / 1.08$ \\
\hline NAVARRA & $8.33 / 5.43$ & $9.23 / 6.60$ & $1.25 / 1.06$ \\
\hline \multicolumn{4}{|l|}{ PAÍS VASCO } \\
\hline Álava & $8.51 / 11.44$ & $6.48 / 13.2$ & $1.23 / 1.46$ \\
\hline Guipúzcoa & $8.47 / 7.19$ & $6.56 / 7.19$ & $1.23 / 1.21$ \\
\hline Vizcaya & $9.87 / 5.17$ & $6.19 / 4.59$ & $1.25 / 1.14$ \\
\hline RIOJÁ, LA & $6.65 / 3.84$ & $8.09 / 4.01$ & $1.18 / 1.11$ \\
\hline
\end{tabular}

\section{CONCLUSIONES}

La tasa de inactividad de la mujer en España sigue siendo elevada y por encima de los países de nuestro entorno económico, aunque en los 
años 90 la mujer se ha incorporado significativamente al mercado laboral. Al mismo tiempo, el paro sigue afectando a la mujer en un notorio mayor grado que a los hombres.

Es sobre todo su mayor grado de instrucción y el mayor nivel de estudios que alcanza,lo que está haciendo cambiar el número de mujeres que trabajan y su categoría profesional. Es patente el aumento de su presencia en ocupaciones de alto nivel, sobre todo en cuanto a directivos de la administración pública (de 21.400 en 1990 a 334.600 en 1996) y profesionales, técnicos y similares (de 633.700 en el año 1990 a 1.022 .000 en 1996), habiendo descendido su número como empleadas administrativas, personal de servicios y en el comercio. Su situación profesional también está cambiando, ascendiendo su papel de empleadora (de 64.800 en 1990 a 104.300 en 1996) y en asalariados, disminuyendo su situación en «ayudas familiares", aunque sigue siendo una situación con elevada presencia.

A pesar de este giro laboral, la mujer se encuentra todavía centrada en determinadas profesiones, tradicionalmente femeninas, y discriminada en su remuneración. Por otro lado, este cambio se centra sobre todo en un determinado tipo de mujeres jóvenes que han modificado las características tradicionales de la mujer trabajadora, pero sigue habiendo todavía un importante grupo, mayoritario, al que en poco afectan las situaciones del cambio.

Se aprecian significativas diferencias regionales en la actividad femenina. Establecidas las correlaciones entre la tasa de actividad femenina y su tasa de empleo, de población por sectores de actividad, de edad de las mujeres demandantes de empleo y de grado de instrucción, se observa que efectivamente es el nivel de instrucción, en el contexto global del país, el que marca las diferencias en la correlación. Por Comunidades Autónomas encontramos que actividad y empleo se correlacionan excepto en Levante, Navarra, Rioja y Cantabria; que la actividad se relaciona con los sectores secundario y terciario de actividad prioritarios en cada caso, quedando el sector primario correlacionado tan sólo en Levante y en las islas. Igualmente, la actividad se relaciona con la población más joven excepto en Castilla-León, Andalucía, País Vasco y Galicia; y con el nivel de estudios, marcándose las diferencias sobre todo en relación con los estudios superiores, con los que no se guarda correlación en Galicia, Aragón, Castilla-León y Andalucía.

\section{BIBLIOGRAFÍA}

INE. Encuesta de Población Activa. Resumen anual 1996.

INE. Encuesta Salarial 1995. 
INEM (1998) «Información sobre Mercado de Trabajo. Resumen de datos del Observatorio Ocupacional. 1996". Madrid. Ministerio de Trabajo y Asuntos Sociales.

Miguel CASTAÑo, Carmen de (1988) "La participación femenina en la actividad económica". Seminario mujer e igualdad de oportunidades en el trabajo. Santander sept 1987.

O.C.D.E. (1986) "La integración de la mujer en la economla". Informes de la O.C.D.E. Madrid. Ministerio de Trabajo y Seguridad Social.

SALLĖ, $M^{z}$ Angeles \& CASAS, Jose Ignacio (1987) "Efectos de la crisis económica sobre el trabajo de las mujeres". Madrid. Instituto de la Mujer. Ministerio de cultura. 